Australian Journal of
Crop Science

AJCS 14(02):213-220 (2020)

ISSN:1835-707

doi: 10.21475/ajcs.20.14.02.p1518

\title{
Mixed models and multivariate approach applied to maize breeding: A useful tool for biofortification
}

\author{
Tiago Corazza da Rosa ${ }^{1}$, Ivan Ricardo Carvalho ${ }^{2 *}$, José Antonio Gonzalez da Silva ${ }^{2}$, Vinícius Jardel \\ Szareski ${ }^{1}$, Maurício Horbach Barbosa ${ }^{1}$, Jessica Fernanda Hoffmann ${ }^{1}$, Ester Mafalda Matter ${ }^{2}$, Christian \\ Szambelam Zimmermann ${ }^{2}$, Valéria Escaio Bubans ${ }^{2}$, Velci Queiróz de Souza ${ }^{3}$
}

\author{
${ }^{1}$ Federal University of Pelotas, Capão do Leão, RS, Brazil \\ ${ }^{2}$ Regional University of Northwest of State of Rio Grande do Sul, ljuí, RS, Brazil \\ ${ }^{3}$ Federal University of Pampa, São Gabriel, RS, Brazil
}

*Corresponding author: carvalho.irc@gmail.com

\section{Abstract}

Biofortification and bioactive compounds enrichment of maize genotypes is a great alternative for mitigating micronutrients deficiency in human and animal diet, and also for improving the benefits of maize for human health. This work aimed to estimate variance components and genetic parameters of bioactive compounds and micronutrients to predict superior maize hybrids from different genetic bases, and to apply the RELM/BLUP methodology to multivariate techniques. The inbreed lines were crossed and the F1 hybrids were grown for evaluations in 2014/2015 and 2015/2016 growing seasons, respectively. Then, micronutrients and bioactive compounds related traits were evaluated. The variance components and genetic parameters were estimated by REML methodology. The BLUP methodology was employed to predict genetic values and to verify the percentages of genetic gain with selection. The predicted genetic values were applied to estimate genetic distances by the Mean Euclidean Distance. The relative contribution of each trait to genetic divergence was evaluated and the principal components analysis determined, proposing the genotypes that are potentially capable to increase a given trait. The presence of genetic variability was evidenced among genotypes, while some of them presented potential for increasing specific traits. The top cross hybrid L64XAS1590 showed the highest estimates for increasing antioxidant-responsible traits, and micronutrients contents such as manganese, cooper, iron and zinc. In general, there was the possibility of achieving genetic gains with selection under application of biofortified and bioactive compounds to enhance maize hybrids through conventional breeding. However, it does not applicable for iron content due to its low estimate of broad sense heritability.

Abbreviations: TP_total phenols; $\mathrm{TF}_{-}$total flavonoids; TC_total carotenoids; $\mathrm{DP}_{-}$antioxidant potential by $\mathrm{DPPH}$; $\mathrm{AB}_{-}$antioxidant

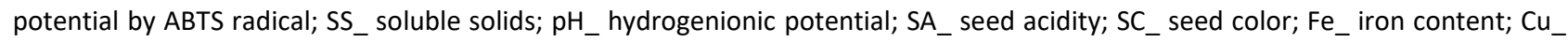
copper content; $\mathrm{Mn}_{-}$manganesecontent; $\mathrm{Na}_{-}$sodium content; $\mathrm{Zn}$ _ zinc content; BLUP_Best linear unbiased prediction; REML_ restricted maximum likelihood; PCA_ principal component analysis; UPGMA_ unweightedpair-group method; ${ }^{+} \widehat{\sigma}_{\mathrm{g}}{ }_{-}$Genotypic variance; $\widehat{\sigma}_{\mathrm{e}_{-}}$residual variance; $\widehat{\sigma}_{\mathrm{P}_{-}}$phenotypic variance; $\mathrm{H}^{2} \mathrm{~g}_{-}$broad sense heritability; $\mathrm{H}^{2} \mathrm{ml}_{-}$heritability of the hybrid's means; Aclinh_selective accuracy; CVgi\%_Coefficient of genetic variation; CVe\%_Coefficient of residual variation; OM_overall mean.

\section{Introduction}

Micronutrient deficiency affects many people around the world, especially in developing countries, where it is considered a public health problem (Bouis et al., 2011). The main source of vitamins and minerals in low-income populations are plant-based staple foods, which often present low levels or low availability of micronutrients (FAO, 2015). Biofortification aims to develop nutritionally enriched crops through conventional plant breeding methods (OrtizMonasterio et al., 2007), prioritizing the increase of iron, zinc and carotenoids (provitamin A), due to the prevalence of their deficiency among children up to five years old and women at childbearing age in developing areas of Africa, Asia and Latin America (Bouis and Welch, 2010).

Plant bioactive compounds are health supporting substances due to their antioxidant activity. They reduce the harmful effects of reactive oxygen species (ROS) and other free radicals, competing for active sites and receptors in diverse cellular structures. Furthermore, they modulate the expression of genes involved in intracellular defense mechanisms against degenerative oxidative processes of cellular structures (Bastos et al., 2009, Sikoraet al., 2008, Wen et al., 2012).

Maize (Zea mays L.) is a crop of major socioeconomic importance around the world. Its wide cultivation and 
versatility of purposes make it one of the most produced cereals worldwide (FAO, 2015). However, its utilization dynamics is different due to economic and cultural issues (Awika, 2011). In developing countries that still face severe food shortages such as southern and eastern Africa, Central America and Mexico, maize is directly consumed in human diet, being an essential source of energy, minerals and other nutrients (Ranum et. al., 2014). In developed countries, where food shortages have been surpassed or the population's diet is based on other staple foods, maize is widely used for animal feed, ethanol production or by the industry (Paes, 2006). For all these reasons, maize is an interesting crop for biofortification.

An efficient and economically feasible alternative to achieve bioactive compounds and micronutrients enhanced (biofortified) maize genotypes is through conventional breeding programs, being necessary to benefit from different sources of genetic variability and different genetic bases. In this sense, single cross hybrids are potentially more productive than other types of hybrids due to the effects of specific combining ability and heterosis. However, it requires improved treats and growing conditions (Nardino et al, 2016). The three-way cross hybrids present uniform phenotype, intermediate yielding potential compared to single cross and double cross hybrids. However, they adapt better to environment variations due to their larger genetic base. The double cross hybrids are originated by crossing two single cross hybrids, and because of their broad genetic constitution, they present greater stability and lower cost of production (Emygdio et al., 2007).

The knowledge about the genotype's genetic value for a particular trait is essential in breeding programs. In this view, statistical models employed to estimate variance components and genetic parameters aid at elaborating the most suitable strategy for selection of traits of interest. Genetic parameters of the traits of interest may be estimated through the restricted maximum likelihood method (REML), providing reliable and applicable estimates to maize breeding (Baretta et al., 2016). The best linear unbiased prediction (BLUP) enables estimation of genetic values and to predict the next generation's new means (Resende and Duarte, 2007), allowing to rank and select the most promising genotypes for traits of interest (Borges et al., 2010).

The knowledge about genetic distances is fundamental in maize breeding, as this information allows improving the efficiency of lineage selection for crossings. Thus, multivariate analysis help breeders in the decision-making process since it allows evaluating a set of traits related to each other, resulting in the coefficients of genetic distance between genotypes (Cruzet al., 2012). For predicting genetic divergence, several multivariate approaches may be applied, standing out the agglomerative methods such as Euclidean distance and principal component analysis (Cruz et al., 2012). The multivariate approaches have been used for prediction of genetic values and to verify genetic distances that may greatly contribute to genetic breeding and biofortification of maize genotypes. These techniques can contribute to increase the accuracy and reliability of inferences by distinguishing genotypes that are phenotypically and genetically have higher values. This reduces the environmental deviations and provides greater gains with selection. Therefore, this work aimed to estimate variance components and genetic parameters of bioactive compounds and micronutrients, to predict the superior maize hybrids of different genetic bases, and to apply the RELM/BLUP methodology for multivariate techniques.

\section{Results and discussion}

The Deviance analysis revealed significance at $5 \%$ of probability trough the chi-square test for all evaluated traits (Table 2). Therefore, the estimates of variance components and genetic parameters present reliability and consistency. The variances of the evaluated traits were compared by percentage, according to methodology proposed by Carvalho et al. (2017). Regarding the trait total phenols (TP), $86 \%$ of its phenotypic variation is caused by genetic causes (Table 2). It is interesting that the largest fraction of the phenotypic variance is originated from genetic causes, as this trait presents great importance for human health. Natural plant antioxidants, as phenolic compounds are involved in regulation of reactive oxygen species content, and they perform an important function as protective compatible osmolyte in scavenging free radicals, and facilitate a correction of altered redox potential (Harre et al., 1999).

The trait total flavonoids (TF) presented $96.5 \%$ of the phenotypic variance occurring due to genetic causes (Table 2). This elevated estimate may contribute to increase the genetic control of TP, as flavonoids and non-flavonoid compounds (Liu, 2004) form total phenols. It also suggests the possibility of incrementing both traits by genetic breeding. The trait total carotenoids (TC) evidenced that 99.1\% of its phenotypic variance is attributed to genetic causes (Table 2), and heritability in the broad sense of 0.99 . José Junior (2014), presented similar results $\left(H^{2}: 98\right)$ evaluating VPAs, single cross and three-way cross maize hybrids, expressing the possibility of achieving genetic gains and superior genotypes (Kimura et al., 2007). These results are very promising for maize biofortification, as important traits for human health as they can be maintained along generations of selection. Carotenoids are a group of pigments responsible for the color of maize grains. They are located in the endosperm, more specifically in the aleurone layer and in the vitreous endosperm of the grains (Gallagher et al., 2004). Maize is one of the few sources of both xanthophilias (lutein and zeaxanthin), constituents of the socalled macular pigments involved in prevention of agerelated macular degeneration (Gama and Silos, 2007). Alphacarotene, beta-carotene and beta-kryptoxanthin are considered essential precursors of vitamin A for preventing hypovitaminosis $A$, which are still being considered a problem of public health in several countries (Butt, 2006). The trait DPPH (DP) refers to the determination of antioxidant potential by the DPPH radical scavenging method. The antioxidant potential was also verified by the $A B T S$ method $(A B)$, using both to increase the results reliability. A similar behavior was found for $D P$ and $A B$, which presented elevated genetic variance of $95.58 \%$ and 93.15\% of the phenotypic variance, respectively (Table 2). These results affirm the elevated estimates of genetic variance verified for the antioxidant responsible traits, 
Table 1. Description of the hybrids and their respective genetic basis.

\begin{tabular}{lccc}
\hline Hybrids & GeneticBasis & Hybrids & GeneticBasis \\
\hline P2530 & Single-cross hybrid & L1 X 30F53 & Top-cross hybrid \\
P30F53 & Single-cross hybrid & L56 X 30F53 & Top-cross hybrid \\
L210 X L272 & Single-cross hybrid & L35 X CD308 & Top-cross hybrid \\
L272 X L288 & Single-cross hybrid & L48 X CD308 & Top-cross hybrid \\
L288 X L272 & Single-cross hybrid & L51 X CD308 & Top-cross hybrid \\
L272 X L210 & Single-cross hybrid & L22 X CD308 & Top-cross hybrid \\
BM3061 & Triple-cross hybrid & L42 X CD308 & Top-cross hybrid \\
L258 X CD308 & Top-cross hybrid & L43 X 30F53 & Top-cross hybrid \\
L261 X CD308 & Top-cross hybrid & BM207 & Double-cross hybrid \\
L66 X AS1590 & Top-cross hybrid & & Double-cross hybrid \\
L64 X AS1590 & Top-cross hybrid & & \\
\hline
\end{tabular}

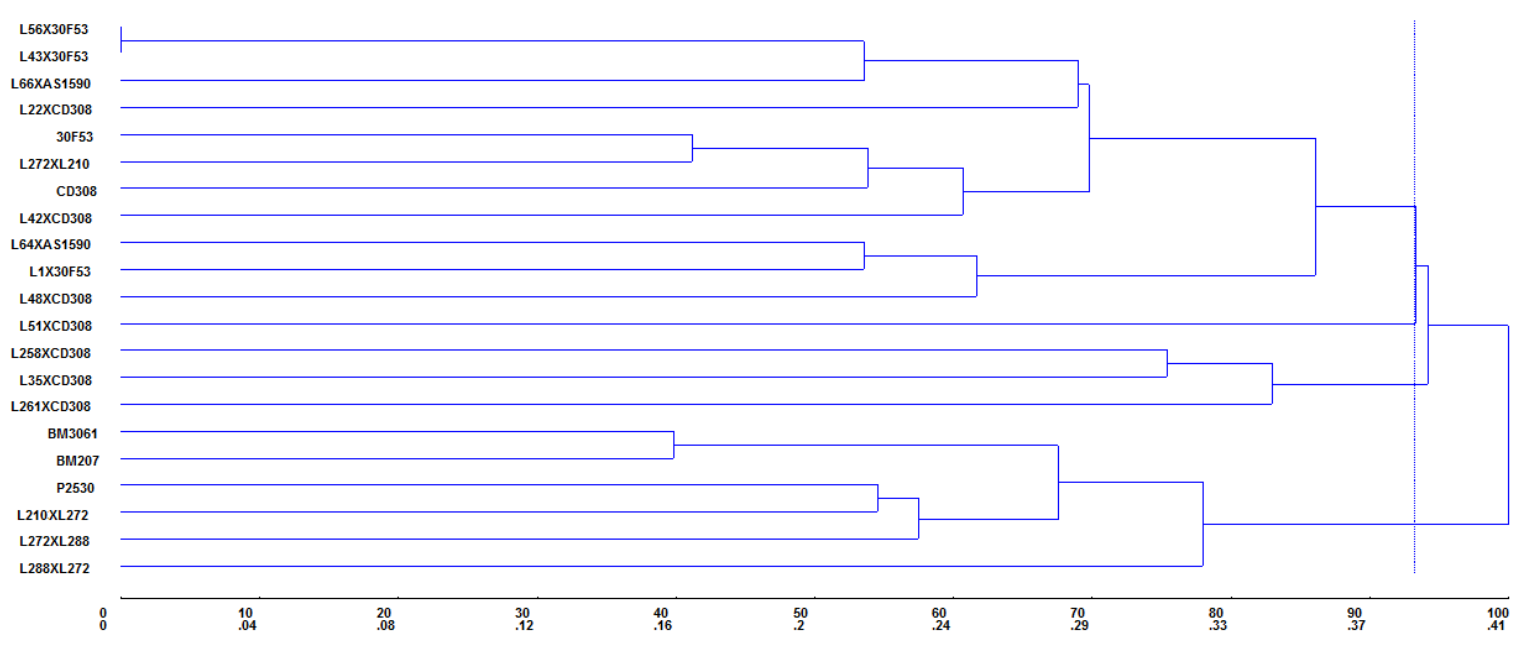

Fig 1. Dendrogram of genetic dissimilarity established by the Unweighted Pair-Group Method using the Arithmetic Average (UPGMA), based on the Euclidean distance for hybrids of different genetic bases.

Table 2: Variance components estimates and genetic parameters (REML) for the different genetic basis hybrids.

\begin{tabular}{|c|c|c|c|c|c|c|c|}
\hline Comp. ofvariance $^{+}$ & $\mathrm{TP}^{++}$ & $\mathrm{TF}$ & $\mathrm{TC}$ & $\mathrm{DP}$ & $A B$ & SS & $\mathrm{pH}$ \\
\hline Deviance $^{+++}$ & $* *$ & $* *$ & $* *$ & $* *$ & $* *$ & $* *$ & $* *$ \\
\hline$\widehat{\sigma}_{\mathrm{g}}$ & 38305.59 & 433505.53 & 4992.66 & 121.25 & 329.17 & 2.30 & 0.04 \\
\hline$\widehat{\sigma}_{\mathrm{e}}$ & 6026.94 & 15680.85 & 44.89 & 5.59 & 24.37 & 0.73 & 0.00 \\
\hline$\widehat{\sigma}_{P}$ & 44332.53 & 449186.38 & 5037.54 & 126.85 & 353.55 & 3.03 & 0.04 \\
\hline $\mathrm{H}^{2} \mathrm{~g}$ & 0.86 & 0.97 & 0.99 & 0.96 & 0.93 & 0.76 & 0.84 \\
\hline $\mathrm{H}^{2} \mathrm{ml}$ & 0.95 & 0.99 & 1.00 & 0.98 & 0.98 & 0.90 & 0.94 \\
\hline Aclinh & 0.97 & 0.99 & 1.00 & 0.99 & 0.99 & 0.95 & 0.97 \\
\hline CVgi\% & 27.50 & 33.82 & 50.64 & 49.14 & 39.91 & 37.31 & 2.96 \\
\hline CVe\% & 10.91 & 6.43 & 4.80 & 10.55 & 10.86 & 21.02 & 1.31 \\
\hline $\mathrm{OM}$ & 711.65 & 1946.55 & 139.53 & 22.41 & 45.46 & 4.07 & 6.34 \\
\hline Comp. ofvariance & SA & SC & $\mathrm{Fe}$ & $\mathrm{Cu}$ & $\mathrm{Mn}$ & $\mathrm{Na}$ & $\mathrm{Zn}$ \\
\hline Deviance & $* *$ & $* *$ & $* *$ & $* *$ & $* *$ & $* *$ & $* *$ \\
\hline$\widehat{\sigma}_{g}$ & 0.01 & 4.82 & 3.96 & 1.48 & 3.03 & 852.13 & 35.59 \\
\hline$\widehat{\sigma}_{\mathrm{e}}^{0}$ & 0.00 & 0.07 & 15.31 & 1.13 & 1.53 & 96.02 & 1.57 \\
\hline$\widehat{\sigma}_{P}$ & 0.01 & 4.89 & 19.27 & 2.61 & 4.56 & 948.16 & 37.16 \\
\hline $\mathrm{H}^{2} \mathrm{~g}$ & 0.92 & 0.99 & 0.21 & 0.57 & 0.66 & 0.90 & 0.96 \\
\hline $\mathrm{H}^{2} \mathrm{ml}$ & 0.97 & 1.00 & 0.44 & 0.80 & 0.86 & 0.96 & 0.99 \\
\hline Aclinh & 0.99 & 1.00 & 0.66 & 0.89 & 0.93 & 0.98 & 0.99 \\
\hline CVgi\% & 23.77 & 2.34 & 7.11 & 32.96 & 14.73 & 22.49 & 20.35 \\
\hline CVe\% & 7.21 & 0.29 & 13.98 & 28.80 & 10.46 & 7.55 & 4.27 \\
\hline OM & 0.32 & 93.22 & 28.00 & 3.69 & 11.82 & 129.77 & 29.32 \\
\hline
\end{tabular}

${ }^{{ } \widehat{\sigma}_{g}}$ : Genotypic variance; $\widehat{\sigma}_{\mathrm{e}}$ : residual variance (environment); $\widehat{\sigma}_{\mathrm{p}}$ : phenotypic variance; $\mathrm{H}^{2}$ : broad sense heritability; $\mathrm{H}^{2}{ }_{\mathrm{ml}}$ : heritability of the hybrid's means; Aclinh: selective accuracy; CVgi\%: Coefficient of genetic variation; CVe\%: Coefficient of residual variation; OM: overall mean. ${ }^{+1}$ TP: Total Phenols; TF:TotalFlavonoids;TC: Total Carotenoids; DP: antioxidant potential by DPPH radical; AB: antioxidant potential by ABTS radical; SS:soluble solids; pH:hydrogenionic potential; SA: seed acidity; Cu: copper; Fe:iron; SC: seed color; Mn: manganese; $\mathrm{Na}$ sodium; $\mathrm{Zn}$ : zinc. ${ }^{++}$Deviance at $5 \%$ of probability by the chi-square test. 


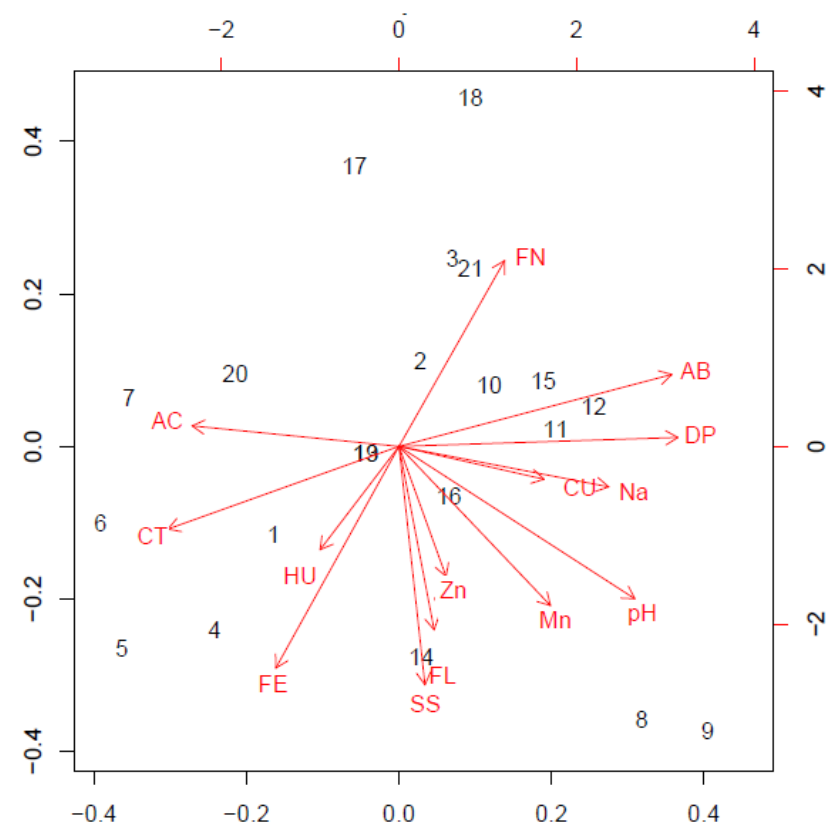

Fig 2. Graphic representation of the Principal Component Analysis (PCA). CP1: 28.86\%; CP2: 17.87\%; CP3: 14.50\%; 1: L56X30F53;2: L43X30F53; 3:L66XAS1590; 4: L22XCD308; 5: 30F53; 6: L272XL210; 7:CD308; 8:L42XCD308; 9: L64XAS1590; 10: L1X30F53; 11: L48XCD308; 12: L51XCD308; 13: L258XCD308; 14: L35XCD308; 15: L261XCD308; 16: BM3061; 17: BM207; 18: P2530; 19: L210XL272; 20: L272XL288; 21: L288XL272. TP: Total Phenols; TF: Total Flavonoids; TC: Total Carotenoids; DP: antioxidant potential by DPPH radical; $A B$ : antioxidant potential by ABTS radical; SS: soluble solids; $\mathrm{pH}$ : hydrogenionic potential; SA: seed acidity; $\mathrm{Cu}$ : copper; Fe: iron; SC: seed color; Mn: manganese; Na: sodium; Zn: zinc.

Table 3. Ranking of the single cross, double cross, three-way cross and top cross maize hybrids evaluated through individual BLUP for the traits antioxidant potential by ABTS radical (AB); antioxidant potential by DPPH radical (DP); total phenols (TP); total flavonoids (TF); total carotenoids (TC); seed color (SC) and soluble solids (SS).

\begin{tabular}{|c|c|c|c|c|c|c|c|}
\hline Ranking & $A B$ & $\mathrm{DP}$ & TP & $\mathrm{TF}$ & $\mathrm{TC}$ & SC & SS \\
\hline $1^{\text {st }}$ & L64XAS1590 & L1X30F53 & BM207 & L272XL288 & P30F53 & L48XCD308 & L42XCD308 \\
\hline $2^{\text {nd }}$ & P2530 & L48XCD308 & L66XAS1590 & L48XCD308 & L22XCD308 & L261XCD308 & L35XCD308 \\
\hline $3^{\text {rd }}$ & L288XL272 & L64XAS1590 & P2530 & L56X30F53 & CD308 & L42XCD308 & L22XCD308 \\
\hline $4^{\text {th }}$ & L42XCD308 & L51XCD308 & ВM3061 & L64XAS1590 & L258XCD308 & L51XCD308 & L43X30F53 \\
\hline $5^{\text {th }}$ & L1X30F53 & L42XCD308 & L288XL272 & L1X30F53 & L210XL272 & L64XAS1590 & L64XAS1590 \\
\hline $6^{\text {th }}$ & BM207 & P2530 & L43X30F53 & L35XCD308 & BM207 & L272XL210 & L258XCD308 \\
\hline $7^{\text {th }}$ & L51XCD308 & L66XAS1590 & L64XAS1590 & L42XCD308 & L272XL288 & P2530 & L210XL272 \\
\hline $8^{\text {th }}$ & L258XCD308 & L258XCD308 & L1X30F53 & $30 F 53$ & L272XL210 & L66XAS1590 & L56X30F53 \\
\hline $9^{\text {th }}$ & L210XL272 & L210XL272 & L258XCD308 & L258XCD308 & L56X30F53 & L288XL272 & $30 F 53$ \\
\hline $10^{\text {th }}$ & L66XAS1590 & L261XCD308 & L210XL272 & L210XL272 & L35XCD308 & L35XCD308 & L272XL210 \\
\hline $11^{\text {th }}$ & L35XCD308 & L288XL272 & L35XCD308 & L22XCD308 & L42XCD308 & L272XL288 & L51XCD308 \\
\hline $12^{\text {th }}$ & L43X30F53 & BM207 & L48XCD308 & L51XCD308 & P2530 & L43X30F53 & L66XAS1590 \\
\hline $13^{\text {th }}$ & L261XCD308 & L43X30F53 & $30 F 53$ & L261XCD308 & ВM3061 & CD308 & CD308 \\
\hline $14^{\text {th }}$ & BM3061 & BM3061 & L51XCD308 & L288XL272 & L64XAS1590 & L56X30F53 & L272XL288 \\
\hline $15^{\text {th }}$ & L48XCD308 & L35XCD308 & L56X30F53 & L66XAS1590 & L1X30F53 & L1X30F53 & L48XCD308 \\
\hline $16^{\text {th }}$ & L22XCD308 & L22XCD308 & L261XCD308 & L43X30F53 & L43X30F53 & $30 F 53$ & L1X30F53 \\
\hline $17^{\text {th }}$ & CD308 & L272XL210 & L22XCD308 & P2530 & L288XL272 & ВМ3061 & ВM3061 \\
\hline $18^{\text {th }}$ & L272XL288 & $30 F 53$ & L42XCD308 & BM3061 & L66XAS1590 & L258XCD308 & BM207 \\
\hline $19^{\text {th }}$ & L56X30F53 & L272XL288 & L272XL210 & BM207 & L261XCD308 & L210XL272 & L288XL272 \\
\hline $20^{\text {th }}$ & L272XL210 & L56X30F53 & CD308 & CD308 & L51XCD308 & L22XCD308 & L261XCD308 \\
\hline 21th & $30 F 53$ & CD308 & L272XL288 & L272XL288 & L48XCD308 & BM207 & P2530 \\
\hline
\end{tabular}


Table 4. Ranking of the single cross, double cross, three-way cross and top cross maize hybrids evaluated through individual BLUP for the traits seed acidity (SA); hydrogenionic potential $(\mathrm{pH})$; manganese content $(\mathrm{Mn})$; cupper content $(\mathrm{Cu})$; iron content (Fe); sodium content (Na); and zinc content ( $\mathrm{Zn})$.

\begin{tabular}{|c|c|c|c|c|c|c|c|}
\hline Ranking & SA & $\mathrm{pH}$ & $\mathrm{Mn}$ & $\mathrm{Cu}$ & $\mathrm{Fe}$ & $\mathrm{Na}$ & $\mathrm{Zn}$ \\
\hline $1^{\text {st }}$ & L272XL210 & L64XAS1590 & BM3061 & BM3061 & $30 F 53$ & L288XL272 & L64XAS1590 \\
\hline $2^{\text {nd }}$ & L22XCD308 & L51XCD308 & L64XAS1590 & L64XAS1590 & L35XCD308 & L42XCD308 & ВM3061 \\
\hline $3^{\text {rd }}$ & L35XCD308 & L35XCD308 & L261XCD308 & $30 F 53$ & L43X30F53 & L64XAS1590 & L261XCD308 \\
\hline $4^{\text {th }}$ & L288XL272 & L42XCD308 & L51XCD308 & L258XCD308 & CD308 & L43X30F53 & L35XCD308 \\
\hline $5^{\text {th }}$ & $30 F 53$ & BM3061 & L22XCD308 & L210XL272 & L42XCD308 & L1X30F53 & $30 F 53$ \\
\hline $6^{\text {th }}$ & BM207 & L22XCD308 & L272XL210 & L272XL210 & L64XAS1590 & L35XCD308 & L56X30F53 \\
\hline $7^{\text {th }}$ & P2530 & L48XCD308 & L35XCD308 & L48XCD308 & L272XL210 & BM3061 & L22XCD308 \\
\hline $8^{\text {th }}$ & CD308 & L258XCD308 & $30 F 53$ & L22XCD308 & L22XCD308 & L66XAS1590 & L42XCD308 \\
\hline $9^{\text {th }}$ & L51XCD308 & L210XL272 & CD308 & CD308 & L1X30F53 & BM207 & L258XCD308 \\
\hline $10^{\text {th }}$ & L258XCD308 & L261XCD308 & L288XL272 & L272XL288 & ВM3061 & L51XCD308 & L210XL272 \\
\hline $11^{\text {th }}$ & L210XL272 & L272XL288 & L272XL288 & L1X30F53 & L56X30F53 & L258XCD308 & BM207 \\
\hline $12^{\text {th }}$ & L66XAS1590 & L1X30F53 & L66XAS1590 & L43X30F53 & L288XL272 & L210XL272 & L48XCD308 \\
\hline $13^{\text {th }}$ & ВM3061 & L56X30F53 & L56X30F53 & L66XAS1590 & L272XL288 & L48XCD308 & L66XAS1590 \\
\hline $14^{\text {th }}$ & L56X30F53 & L43X30F53 & BM207 & L51XCD308 & L258XCD308 & P2530 & L51XCD308 \\
\hline $15^{\text {th }}$ & L43X30F53 & BM207 & L42XCD308 & L288XL272 & L210XL272 & L261XCD308 & L1X30F53 \\
\hline $16^{\text {th }}$ & L1X30F53 & L288XL272 & L258XCD308 & BM207 & L66XAS1590 & L22XCD308 & P2530 \\
\hline $17^{\text {th }}$ & L48XCD308 & P2530 & L210XL272 & L56X30F53 & L48XCD308 & L56X30F53 & L43X30F53 \\
\hline $18^{\text {th }}$ & L272XL288 & L66XAS1590 & P2530 & L35XCD308 & L261XCD308 & L272XL210 & CD308 \\
\hline $19^{\text {th }}$ & L261XCD308 & $30 F 53$ & L48XCD308 & L261XCD308 & P2530 & 30F53 & L272XL288 \\
\hline $20^{\text {th }}$ & L64XAS1590 & CD308 & L43X30F53 & L42XCD308 & BM207 & CD308 & L288XL272 \\
\hline 21th & L42XCD308 & L272XL210 & L1X30F53 & P2530 & L51XCD308 & L272XL288 & L272XL210 \\
\hline
\end{tabular}

Table 5. Relative contribution to genetic diversity based on predicted genotypic values for traits evaluated in maize hybrids through Singh's methodology (1981).

\begin{tabular}{lc}
\hline Traits $^{+}$ & Relative Contribution (\%) \\
\hline TP & 11.19 \\
DP & 10.13 \\
TC & 9.00 \\
AB & 8.23 \\
Cu & 7.82 \\
TF & 7.37 \\
pH & 7.20 \\
Zn & 6.75 \\
SA & 5.98 \\
Na & 5.53 \\
Mn & 5.51 \\
SS & 5.46 \\
Fe & 5.36 \\
SC & 4.46 \\
\hline
\end{tabular}

${ }^{+}$TP: total phenols; DP: antioxidant potential by DPPH radical; TC: total carotenoids; AB: antioxidant potential by ABTS radical; Cu: cupper; TF: total flavonoids; pH: hydrogenionic potential; Zn: zinc; SA: seed acidity; Na: sodium; Mn; manganese; SS: soluble solids; Fe: iron; SC: seed color.

evidencing the possibility of breeding bioactive compounds and nutrients enhanced maize.

The micronutrients copper (Cu), zinc $(\mathrm{Zn})$ and manganese $(\mathrm{Mn})$ constitute the superoxide dismutaseenzymes (SODs), which take part in the body's defense against reactive oxygen species (Stipanuk, 2000). There is an agreement that mineral content in edible parts of plants is dependent on their availability for absorption from the soil, followed by their reallocation in the tissues that will serve as food (Welch and Graham, 2005). However, several authors affirm that mineral contents vary in function of genotype (Ahmadi et al, 1993; Wardyn, 2004). Regarding the trait $\mathrm{Cu}, 56.7 \%$ of the phenotypic variance may be explained by genetic causes (Table 2). A similar pattern was verified for $\mathrm{Mn}$, which presented $66.44 \%$ of genotypic variance (Table 2 ). Regarding the content of $\mathrm{Zn}, 95.77 \%$ of the phenotypic variance occurred due to genetic causes (Table 2). A distinct behavior was evidenced by $\mathrm{Fe}$, which presented only $25.86 \%$ of phenotypic variance attributed to genetic causes, while the other $74.14 \%$ was due to residual variance (Table 2), which made the selection of genotypes for increasing this trait difficult. The $\mathrm{Na}$ content presented $89.88 \%$ of genotypic variance (Table 2 ), being possible to achieve genetic gains with selection.

Soluble solids content (SS) (Table 2) is used as an indirect measure of the grains sugar content. It also gathers other dissolved substances, such as organic aciditys, vitamins, phenolic compounds, pectins. However, sugars may constitute $85-90 \%$ of the soluble solids (Chitarra, 2000). Thus, the increment of soluble solids in the grains result in a higher production of functional components such as phenolic compounds, vitamins and organic aciditys. From the phenotypic variance verified for this trait, it is estimated that approximately $75.9 \%$ occur as a function of the genetic 
variance. The $\mathrm{pH}$ is proportional to the fraction of soluble sugars, and inversely proportional to seed acidity (SA) (Carvalho, 2016). For both traits, the phenotypic variances were explained totally, by their respective genotypic variances (Table 2 ), allowing to achieve gains with selection. The heritability estimated in the broad sense corresponds to the proportion of phenotypic variability caused by genetic causes, considering effects of dominance, additivity and epistasis. According to classification described by Resende (2002) heritability is considered of low magnitude when $\widehat{H}_{b}^{2}<$ 0.15 , intermediate magnitude between $0.15<\widehat{H}_{b}^{2}<0.50$ and of high magnitude when $\widehat{H}_{b}^{2}>0.50$. The evaluated traits presented high broad sense heritabilities, except Fe $\left(\widehat{H}_{b}^{2}=\right.$ 0.21 ), evidencing the great influence of environment in this trait's phenotypic expression. These results reaffirm those previously stated by the genotypic variances.

The selective accuracy (Aclinh) reflects the quality of procedures and results used to predict genetic values. This parameter is associated with precision of selection and refers to the correlation between predicted genetic values and true genetic values of the genotypes (Pimentel et al., 2014). Aclinh values range from 0 to 1 , and are classified as very high (Aclinh $\geq 0.90$ ), high (0.70 $\leq$ Aclinh <0.90), moderate $(0.50 \leq$ Aclinh < 0.70$)$ and low (Aclinh <0.50) (Resende and Duarte, 2007). Accuracy values higher than 0.70 are sufficient to provide a precise and efficient inference about genotypes genetic value, and because it is a measure associated with precision in selection, accuracy is the main element of genetic progress that may be altered by the breeder, maximizing genetic gains (Resende, 2002). Most of the evaluated traits presented very high aclinh estimates (Table 2).

The coefficient of genetic variation $(\mathrm{CVgi})$ is a parameter commonly used to compare the genetic variability evidenced for a trait (Resende, 2002). The coefficients of genetic variation ranged from low to very high in the set of evaluated traits, varying from $2.34 \%$ (SC) to $50.64 \%$ (TC), which expresses the high genetic variability among genotypes. The coefficient of residual variation $\left(C V_{e}\right)$ were considered low to intermediate for majority of the evaluated traits, demonstrating precision in conducting the experiment and expressing reliability of the data. According to Vencovsky (1987), a relation between $C V_{g i}$ and $C V_{e}$ of 1 or more reflects a favorable situation to achieve gains with selection. For all traits except Fe, the $C V_{g i}$ was higher than $C V_{e}$, which indicates the possibility of achieving gains with selection.

The top cross hybrid L64XAS1590 was among the highest ranked genotypes through the best linear unbiased prediction (individual BLUP). This high ranking was based on predicted genotypic effects of genotypes for antioxidant potential of ABTS $(A B), D P P H(D H)$, total phenols (TP) and total flavonoids (TF) (Table 3 ). It evidences the potential of this hybrid for maize breeding programs aiming at increasing antioxidant potential related traits. Regarding the traits such as total carotenoids (TC) and seed color (SC), the occurrence of hybrids in high ranking positions was not verified (Table 3). This result suggests the interference of another pigment influencing seed color, possibly anthocyanins, which should be considered in future studies. The single cross hybrid P30F53 was the first ranked for TC, followed by the top cross hybrid L22XCD308, while the top cross hybrids L48XCD308 and L261XCD308 were the highest ranked for SC. The top cross hybrid $\mathrm{L} 35 \mathrm{XCD} 308$ was ranked at the three first positions, considering soluble solid (SS) (Table 3), seed acidity (SA) and $\mathrm{pH}$ (Table 4). The top cross hybrid L22XCD308 also ranked in the top positions for these traits. The top cross hybrid L64XAS1590 was ranked in the top positions for manganese (Mn), copper (Cu), iron (Fe), sodium ( $\mathrm{Na}$ ) and zinc ( $\mathrm{Zn}$ ) contents (Table 4), demonstrating its potential to be used in breeding programs aimed at incrementing these minerals.

The predicted genetic distance verified through the mean Euclidean distance for the set of analyzed hybrids presented an average of 0.27 . The cut-off point (0.38) enabled to visualize four groups of genotypes (Figure 1). Group one was composed by six hybrids (BM3061; BM207; P2530; L210XL272; L272XL288; L288XL272) with the presence of single cross, double cross and three-way cross maize hybrids. Group two was composed by three top-cross maize hybrids (L261XCD308; L35XCD308; L258XCD308), where the double cross hybrid $\mathrm{CD} 308$ was used as tester. The male genitor was observed in all genotypes of this group. Group three was composed of only one top-cross hybrid (L51XCD308), and group four by eleven hybrids (L48XCD308; L1X30F53; L64XAS1590; L42XCD308; CD308; L272XL210; 30F53; L22XCD308; L66XAS1590; L43X30F53; L56X30F53), evidencing the genetic variability among genotypes and different genetic basis.

The relative contribution revealed that total phenols (TP) (11.19\%), antioxidant potential by DPPH method (DP) (10.13), total carotenoids (TC) (9.00\%), antioxidant potential by $A B T S$ method $(A B)(8.23 \%)$ and copper content $(C u)$ $(7.82 \%)$ were the traits that most contributed to explain the differences expressed by variation in the predicted genetic values of the tested hybrids (Table 5). The interest in evaluating traits' relative contribution is the possibility of discarding those with little participation in genotypes discrimination, reducing labor, time and financial resources spent on experimentation. However, since all evaluated traits are important for maize biofortification, and becauuse no low contributing trait was observed, the exclusion of characters is not recommended.

The principal component analysis (PCA) allows to condense the largest amount of original information contained in $p$ variables $(p=14)$ into two orthogonal latent variables called principal components, which are linear combinations of the original variables created with the two largest eigenvalues of the covariance matrix (Hair et al., 2005). Therefore, the initial set of fourteen variables is expressed by two new latent variables, which are plotted in a two-dimensional figure (Figure 2). The PCA allows visualizing the possible affinity of genotypes to express certain trait(s), where it is verified that genotypes L66XAS1590 and L288XL272 presented proximity to the trait total phenols (TP). The genotype L35XCD308 presented proximity to the total flavonoids (TF) and soluble solids (SS). In addition, the genotype L56X30F53 showed proximity to seed color (SC), genotype CD308 with seed acidity (SA), and genotype L272XL210 with total carotenoids (TC). Thereby, these hybrids should be considered in breeding programs that aim to increase these specific traits.

\section{Materials and methods}

The experiment was conducted at the Genomic and Plant Breeding Center of the Federal University of Pelotas. The genotypes were crossed and cultivated during the 2014/2015 and 2015/2016 growing seasons, respectively, at 
the Palma Agricultural Center, in the city of Capão do Leão -

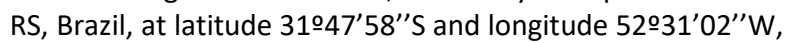
with altitude of 13.2 meters $(\mathrm{m})$. According to Köppen, the climate is classified as subtropical $\mathrm{Cfa}$, and the soil is characterized as Dystrophic Yellow Red Argisol (EMBRAPA, 2006). The experimental design was randomized blocks containing 21 maize hybrids of different genetic basis (Table 1) arranged in three replicates.

Seeding occurred in the first half of December 2015, with population density of 80,000 plants per hectare. The base fertilization consisted of $350 \mathrm{~kg} \mathrm{ha}^{-1}$ of NPK in the formulation 10-20-20. For topdressing, $110 \mathrm{~kg} \mathrm{ha}^{-1}$ of nitrogen in the amidic form was applied at the $V_{4}$ phenological stage. The control of weeds and pests were preventively carried out to reduce biotic effects in the experiment results. The experimental unit consisted of two lines of five meters $(\mathrm{m})$ length, spaced $0.50 \mathrm{~m}$. The harvest occurred in the second half of April 2016, when all genotypes presented foliar senescence.

The evaluated traits were: total phenols (TP) in $\mu \mathrm{g} \mathrm{g}^{-1}$ (Singleton and Rossi, 1965); total flavonoids (TF) in $\mathrm{mg} \mathrm{g}^{-1}$ (Zhishean et al., 1999); total carotenoids (TC) in $\mathrm{mg} \mathrm{g}^{-1}$ (AOAC, 2005); antioxidant potential by DPPH (DP), in inhibition percentage (Brand-Williams et al., 1995); antioxidant potential by $A B T S$ radical (AB), in inhibition percentage (Rufino et al., 2007); soluble solids (SS) in ${ }^{\circ}$ Brix (AOAC, 2005); Hydrogenionic potential $(\mathrm{pH})$; seed acidity $(\mathrm{SA})$, in percentage of citric acid; seed color (SC) in hue angle; and the contents of iron ( $\mathrm{Fe})$; copper ( $\mathrm{Cu})$;manganese $(\mathrm{Mn})$; sodium $(\mathrm{Na})$ and zinc $(\mathrm{Zn})$, which were expressed in $\mathrm{mg}$ $\mathrm{Kg}^{-1}$ (Tedesco et al., 1995).

The data were submitted to normality test by Shapiro and Wilk (1965), and the deviance analysis was performed at 5\% of probability by the chi-square test $\left(X^{2}\right)$ to identify the significance of the traits. For estimating variance components and genetic parameters of the hybrids by REML, the model 21 (Resende, 2016) was used. It was followed the statistical model $y=X r+Z g+e$, where: $y$ : is the data vector, $r$ : are the effects of repetitions (fixed) added to the overall mean; $e$ : are the residue effects (random). The variance components that verified were: genetic variance $\left(\sigma^{2} g\right)$, residual variance $\left(\sigma^{2} e\right)$, phenotypic variance $\left(\sigma^{2} p\right)$, broad sense heritability $\left(H^{2} g\right)$, broad sense heritability of the hybrids average $\left(H^{2} \mathrm{ml}\right)$, accuracy of hybrids selection (Aclinh), coefficient of residual variation (CVe) and overall mean of the experiment (OM).

Single Best Linear Unbiased Prediction (BLUP) were estimated to rank the genotypes $(R)$, to evidence the predicted genetic effects $(G)$, to predict the genetic value $(U+G)$, and to achieve the percentage of genetic gain with selection (Gain\%) and new mean (NM). The analyzes were performed using the Selegen ${ }^{\circledast}$ statistical software (Resende, 2016).

Based on genetic values $(U+G)$ predicted by the BLUB methodology, the Mean Euclidean Distance was obtained, and the dendrogram was assembled through the UPGMA (Unweighted Pair-Group Method using the Arithmetic Average) method. The cut-off point was established by adding one standard deviation to the mean, dividing the dendrogram and displaying groups of genotypes. The trait's relative contribution for genetic divergence was performed according to methodology proposed by Singh (1981), and the principal components analysis (PCA) with biplot representation (Johnson andWichern, 1982) to determine which genotypes have potential to increase a given trait. For statistical analysis the software Genes ${ }^{\bullet}(\mathrm{Cruz}, 2013)$ and $R^{\circ}(R$ Core Team, 2015) was used.

\section{Conclusions}

There is the possibility of achieving genetic gains with selection and to develop biofortified and bioactive compounds enhanced maize hybrids through conventional breeding. However, it does not apply for iron content due to its low estimate of broad sense heritability. Among the evaluated genotypes, the most promising for antioxidant potential was the top cross hybrid L64XAS1590. The top cross hybrid L35XCD308 presented potential to be used by breeding programs aimed at increasing soluble solids, seed acidity and $\mathrm{pH}$ potential. The top cross hybrid L64XAS1590 presents potential to be employed by breeding programs aimed at increasing mineral contents such as manganese, copper, iron, sodium and zinc. The evaluated genotypes present genetic variability for the set of evaluated traits. The closest relation verified through Principal Component Analysis were between the hybrids L66XAS1590 and L288XL272 with total phenols, and the hybrid L35XCD308 with total flavonoids and soluble solids.

\section{Acknowledgements}

The authors wish to thank the National Council for Scientific and Technological Development (CNPq), and the Coordination for the Improvement of Higher Education Personnel (CAPES), for the support.

\section{References}

Ahmadi M (1993) Grain yield and mineral composition of corn as influenced by endosperm type and nitrogen. Communications of Soil Science. 24: 2409-2426.

Awika JM (2011) Advances in Cereal Science: Implications to Food Processing and Health Promotion. American Chemical Society.1089: 1-13.

AOAC (2005) Official methods of analysis of the AOAC International. Gaithersburg. United States of American.

Baretta D, Nardino M, Carvalho IR, Oliveira AC, Souza VQ, Maia LC (2016) Performance of maize genotypes of Rio Grande do Sul using mixed models. Científica. 44(3):403411.

Bastos D, Rogero HM, Marcelo MA (2009) Mecanismos de ação de compostos bioativos dos alimentos no contexto de processos inflamatórios relacionados à obesidade. Arquivos Brasileiros de Endocrinologia Metabólica. 53(5):646-656.

Borges V, Ferreira PV, Soares L, Santos GM, Santos AMM (2010) Selection of sweet potato clons by the REML/BLUP procedure. ActaScientiarum Agronomy. 32(4):643-649.

Bouis HE, Hotz E, McClafferty B, Meenakshi JV, Pfeiffer WH (2011) Biofortification: a new tool to reduce micronutrient malnutrition. Food and Nutrition Bulletin. 32(1):31-40.

Bouis HE, Welch RM (2010) Biofortification- a sustainable agricultural strategy for reducing micronutrient malnutrition in the global South. Crop Science. 50:20-32.

Brand-Williams W, Cuvelier M, Berset C (1995) Use of a free radical method to evaluate antioxidant activity. Food Science and Technology. 28:25-30.

Butt MS (2006) Preparation and characterization of cake rusks by using red palm oil fortified shortening. Food Science and Technology International. 12:85-90. 
Chitarra MIF (2000) Tecnologia e qualidade pós-colheita de frutos e hortaliças. UFLA/FAEPE Press, Lavras.

Carvalho IR, Nardino M, Demari GH, Pelegrin AJ, Ferrari M, Szareski VJ, Oliveira VF, Barbosa MH, Souza VQ, Oliveira AC, Maia LC (2017) Components of variance and interrelationofimportantetraits for maize (Zea mays) breeding. Australian Journal of Crop Science. 11(8):982-988.

Cruz CD (2013) Genes - a software package for analysis in experimental statistics and quantitative genetics. Acta Scientiarum Agronomy. 35:271-276.

Cruz CD, Regazzi AJ, Carneiro PCS (2012) Modelos biométricos aplicados ao melhoramento genético. UFV Press, Viçosa.

EMBRAPA - National Center of Soil Research (2006) Brazilian System of Soil Classification, EMBRAPA Press, Rio de Janeiro.

Emygdio BM, Ignaczak JC, Cargnelutti Filho A (2007) Grain yield potential of commercial single-cross, three-way cross and two-way cross maize hybrids. Revista Brasileira de Milho e Sorgo. 6:95-103.

FAO (2015) The State of Food Insecurity in the World. FAO, Rome.

Gallagher CE (2004) Gene grasses. Plant Physiology. 135:1776-1783.

Gama JJT, Silos CM (2007) Effect of thermal pasteurization and concentration on carotenoid composition of Brazilian Valencia orange juice. Food Chemistry. 100:1686-1690.

Hair JF, Anderson RE, Tatham RL, Black W (2009) Análisemultivariada de dados. Bookman, Porto Alegre.

Johnson RA, Wichern DW (1982) Apllied multivariate statistical analysis. Englewood Cliffs: Prentice Hall.

Kimura M, Kobori CN, Rodriguez-Amaya DB, Nestel P (2007) Screening and HPLC methods for carotenoids in sweet potato, cassava and maize for plant breeding trials. Food Chemistry. 100:1734-1746.

Liu RH (2004) Potencial synergy of phytochemicals in cancer prevention: mechanism of action. Journal of Nutrition. 134: 3479-3485.

Nardino M, Baretta D, Carvalho IR, Follmann DN, Konflanz VA, Souza VQ, Oliveira AC, Maia LC (2016) Correlações fenotípica, genética e de ambiente entre caracteres de milho híbrido da região sul doBrasil. Revista Brasileira de Biometria. 34:379-394.

Ortiz-Monasterio JI, Palacios-Rojas N, Meng E, Pixley K, Trethowanand K, Peña RJ (2007) Enhancing the mineral and vitamin content of wheat and maize through plant breeding. Journal of Cereal Science. 46:293-307.

Pimentel AJB, Guimarães JFR, Souza MA, Resende MDV, Moura LM, Ribeiro G (2014) Estimates of genetic parameters and prediction of additive genetic value of wheat using mixed models. Brazilian Journal of Agricultural Research. 49:882-890.
Ranum P, Peña-Rosas JP, Garcia-Casal MN (2014) Global maize production, utilization, and consumption. New York Academy of Science. 1312:105-112.

R Core Team (2015) R: A language and environment for statistical computing. R Foundation for Statistical Computing, Vienna, AU.

Resende MDV, Duarte JB (2007) Precision and quality control in variety trials. Pesquisa Agropecuária Tropical. 37:182-194.

Resende MDV (2002) Genética Biométrica e Estatística no Melhoramento de Plantas Perenes. Brasilia: Embrapa informações tecnológicas.

Resende MDV (2016) Software Selegen-REML/BLUP: a useful tool for plant breeding. Crop Breeding and Applied Biotechnology. 16:330-339.

Rufino MSM, Alves RE, Brito ES, Morais SM, Sampaio CG, Pérez-Jiménez J, Saura-Calixto FD (2007) Determination of the total antioxidant activity in fruits for the capture of free radical ABTS. Embrapa Press, Brazilia.

Sikora E, Cieslik E, Leszczynska T, Filipiak FA, Pisulewski PM (2008) The antioxidant activity of selected cruciferous vegetables subjected to aquathermal processing. Food Chemistry. 107:55-59.

Singh D (1981) The relative importance of characters affecting genetic divergence. The Indian Journal of Genetic and Plant Breeding. 41:237-245.

Singleton VL, Rossi JAJ (1965) Colorimetry of total phenolics with phosphomolybdic-acidity reagents. American Journal of Enology and Viticulture. 16:144-158.

Stipanuk MH (2000) Biochemical and physiological aspects of human nutrition. W.S. Saunders Company, Phyladelphia.

Tedesco MJ, Gianello C, Bissani CA, Bohnen H, Volkweiss SJ (1995) Soil analysis, plants and other materials. Porto Alegre. Brazil.

Vencovsky R (1987) Herança quantitativa.In: Paterniani, E,Viegas, GP. Melhoramento e produção de milho. Fundação Cargill, Campinas.

Wardyn BM (2004) Resource allocation in a breeding program for phosphorus concentration in maize grain. Crop Science. 44:753-757.

Welch RM, Graham RD (2005) Agriculture: the real nexus for enhancing bioavailable micronutrients in food crops. Journal of Trace Elements in Medicine and Biology. 18:299-307.

Wen B, Liu Y, Wan P, Wu T, Zhang S, Shan X, Lu J (2012) Toxic effects of chlortetracycline on maize growth, reactive oxygen species generation and the antioxidant response. Journal of Environmental Science. 24:1099-1105.

Zhishen J, Mengcheng T, Jianming W (1999) The determination of flavonoid contents in mulberry and their scavenging effects on superoxide radicals. Food Chemistry. 64:555-559. 